\title{
Preliminary Investigation on Buxtonella sulcata (Jameson, 1926) (Ciliphora: Trichostomatidae) in Egyptian Ruminants
}

\author{
K. Sultan, R. E., Khalafalla, M. A. Elseify \\ Department of Parasitology, Faculty of Veterinary Medicine, Kafr El-Sheikh University, Egypt
}

\begin{abstract}
Buxtonella sulcata (Jameson, 1926) is an intestinal protozoan of large ruminants, with scanty information and contradictious reports about its pathogenesity. This work aimed to investigate the prevalence rate of $B$. sulcata in Egypt. Forty eight cases collected from cattle $(n=29)$ and buffaloes $(n=19)$ from El-Mahalla El-Kubra area, Al-Gharbiya province. Samples were examined for the presence $B$. sulcata. The overall infection rate was $41.6 \%(20 / 48)$, in cattle $48.2 \%(14 / 29)$ and in buffalo 31.5\% (6/19). This is the first study on B. sulcata in Egyptian ruminants also highlights the situation of intestinal ciliates of ruminant animals and provides basic information for the future work of intestinal ciliates of animals and man.
\end{abstract}

Buxtonella sulcata (Jameson, 1926) is a ciliate protozoon inhabiting the large intestines of cattle and buffaloes. The presence of B.sulcata in cattle and buffaloes feces have been reported from many countries ( Tomoczuk et al., 2005; Al-Saffar et al., 2010; Jiménez et al., 2010).

Controversy views about the pathogencity of B. sulcata are still present. Becker (1932); Lapage (1956) assumed its commensal nature, but other reports (e.g. Tomczuk et al., 2005; Göz et al., 2006; Al-Saffar et al., 2010) claimed the association of high incidence and intensity of $B$. sulcata with diarrhea in cattle.

Buxtonella sulcata is usually misdiagnosed with Balantidium coli (Malmsten, 1857) another intestinal ciliate which according to our knowledge is the only known pathogenic ciliate for animals and man. B. coli main host is swine (Wenyon, 1926; Levine, 1985), but it could infect other animal species (Headley et al., 2008).

Due to all following causes; this work aimed to determine the prevalence of $B$. sulcata in cattle and buffaloes in Egypt; (1) the morphological similarity in-between $B$. sulcata and $B$. coli trphozoites and cysts as shown earlier (Rees, 1931; Lynn, 2008); (2) the difficulty of staining and cultivation of $B$. coli and other ciliates; the routine diagnosis of intestinal ciliates infection is by coprological examination which has doubtful results and require experience (Schuster and Ramirez-Avila, 2008; Ndao, 2009); (3) consequently the possibility of misidentification of the intestinal ciliate which could found in different animal's feces as $B$. coli even if it is the first cite in the host species is present (Ponce-Gordo et al., 2008).

\section{Material and methods}

Study Area and samples. During spring, 2012; fecal samples were collected from a total of 48 , cattle $(n=29)$ and buffaloes $(n=19)$ in El-Mahalla El-Kubra area, Al-Gharbiya province. Each sample labeled individually; preserved immediately after collection in separate plastic containers with neutral formalin $10 \%$ and transferred to the lab for further examination.

Laboratory examination. Samples were processed for morphological examination by formalin-ethyl ether concentration method (Garcia, 1999); wet mounts from sediments were stained with Lugol's iodine 5\% and examined under light microscope at high magnification. Identification and classification of B.sulcata was done according to Rees (1930); Lapage (1956); Lynn (2008).

\section{Results}

Out of 48 examined fecal samples, 20 (41.6\%) were positive, of which 14 cattle out of $29(48.2 \%)$ and 6 buffaloes out of 19 (31.5\%) found to be infected with Buxtonella sulcata.

Buxtonella sulcata observed cysts were round in diameter ranging between $68-120 \mu \mathrm{m}$ (with a mean of $84 \mu \mathrm{m}$ ), with obviously seen large nucleus (macronucleus) and in front of a smaller clearly seen round one (micronucleus) (Figs. 1 and 3 A), clear cyst wall of encysted trophozoites could be seen even without staining (Fig. 1 A ). While, B. sulcata vegetative forms were few, oval in shape, sized $84-120 \mu \mathrm{m}$ in length $\mathrm{x} 60-90 \mu \mathrm{m}$ in width (with an average of $120 \times 84 \mu \mathrm{m})$. The whole body covered by clear long cilia (Figs. 2 and 3 B). Kidney shape macronucleus and a smaller micronucleus were also observed. The characteristic grooves (Fig.3 B), cytopyge and cytostome located at the 
posterioventral position (Figs. $2 \mathrm{~B}$ and $3 \mathrm{~B}$ ) were also noticed.

\section{Discussion}

The total percentage of infection among all examined samples was $41.6 \%$, being higher than recorded before from calves in Turkey (Göz et al., 2006); cattle from Iraq (Ala-Saffar et al., 2010), \%) and cattle in Korea (Hong and Youn, 1995), but much lower than findings of Hayashi et al., 1971 in Japan (64 \%).

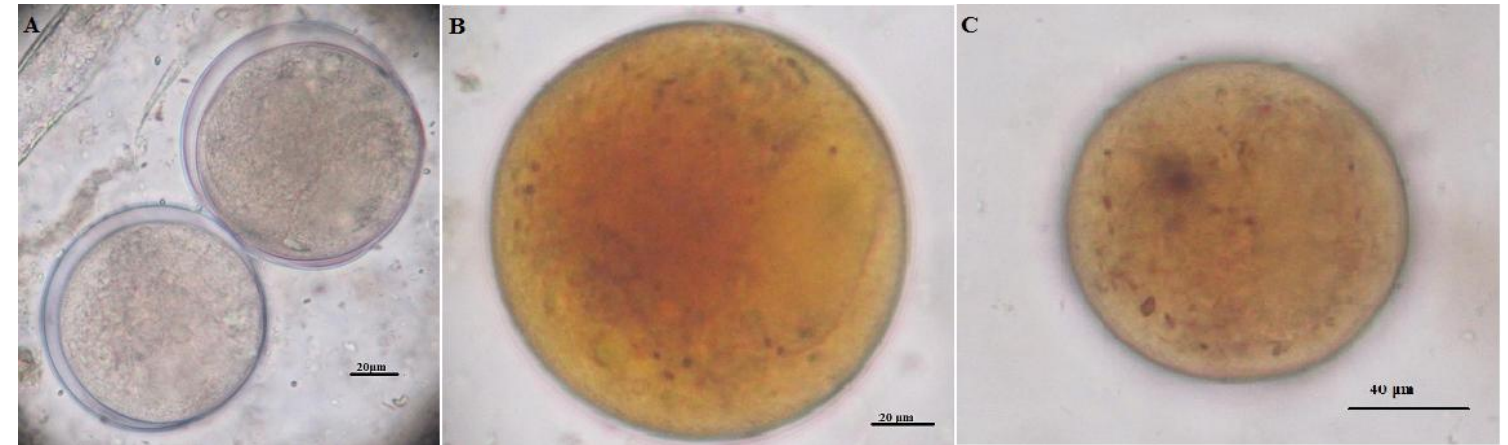

Fig. (1): Buxtonella sulcata cyst.

A: Unstained. Note the clear cyst wall, and the macronucleus which appears in the upper cyst. B: Stained, note the kidney shape macronucelus.

C: Stained, note the round clear micronuclus in front of the macronucleus.
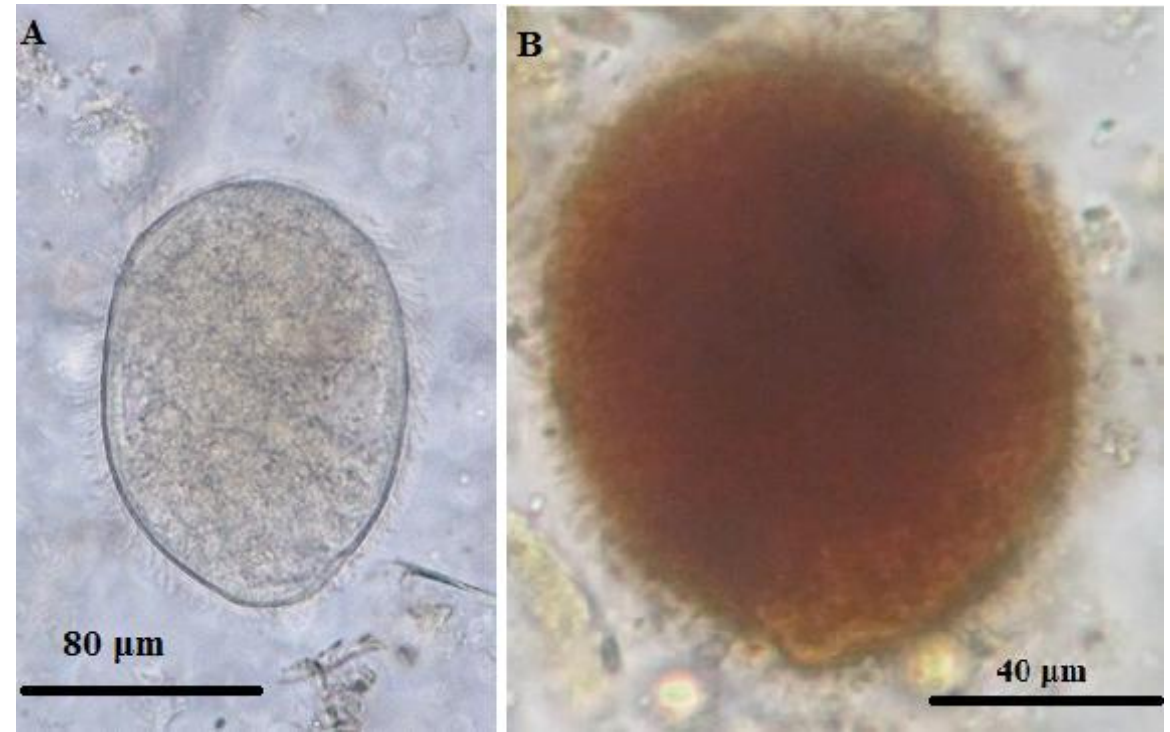

Fig. (2): Buxtonella sulcata trophozoites.

A: Unstained, note the cilia.

B: Stained, note the cilia, two openings in the posterior end.

A

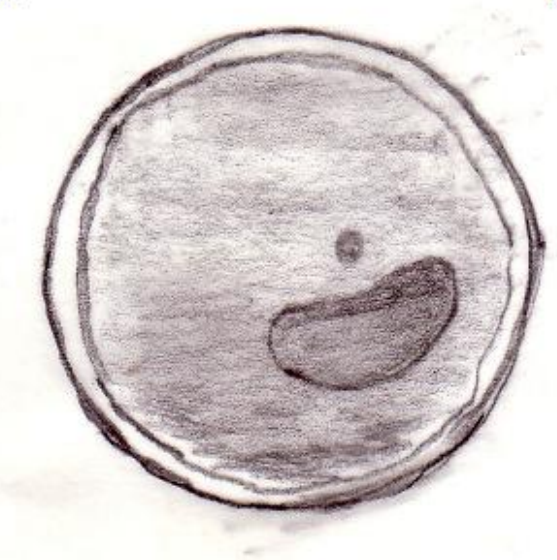

B

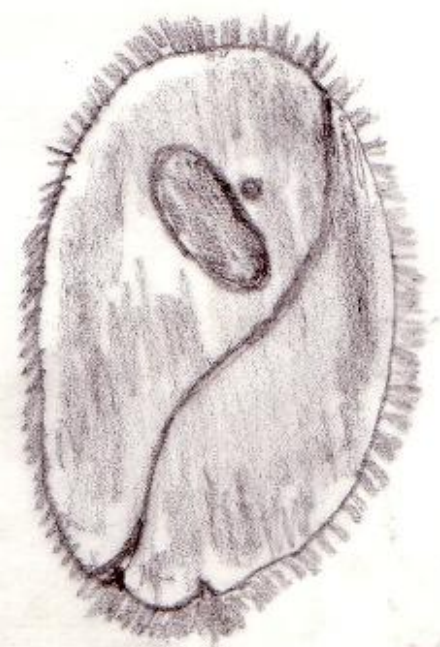

Fig. (3): Hand drawing of Buxtonella sulcata.

A: Cyst.

B: Trophozoite. 
This variation in the percentage of infection with $B$. sulcata in-between these studies and the current work could be attributed to many factors including environmental, mangemental and immunological factors of the examined animals, in accordance to Al-Saffar et al., (2010). Also, a seasonal variation of the percentage of infection with B.sulcata was observed before (Hong and Youn, 1995). The higher incidence of $B$. sulcata in examined cattle than in buffaloes found in this study disagrees with the results of Lubinsky, (1957); Mamatha and Placid, (2006).

The morpho-metrical results of the trphozoites and cysts of B.sulcata in this study are in agreement with other previous studies (Rees, 1931; Hayashi et al., 1971; Al-Saffar et al., 2010). The most obvious morphological character of the trophozoites is the presence of a curved groove (Fig. 3 B) which runs from the anterior end to the posterior end (Rees, 1930; Kudo, 1931).

Buxtonella sulcata is frequently found during the fecal examination of animals to reveal infection with gastrointestinal parasites (Jiménez et al., 2010). The intestinal ciliates found in ruminant commonly identified as $B$. coli (Cooper and Gulati, 1926; Bilal, et al., 2009); or B. sulcata (Rees, 1931; Becker, 1932; Lapage, 1956; Tomczuk et al., 2005; Gőz et al., 2006; Al-Saffar et al., 2010). While in camels the taxonomy and identification of ciliate species in the intestinal tract is not clear, as some authors identify the intestinal species as $B$. coli (Abubaker et al., 2000), others identified it as Infindubilorum cameli (Levine, 1985).

Levine (1985) suggested that the species present in ruminants (i.e. cattle, buffaloes, camels) is actually $B$. sulcata; this view is supported by our results and other works done on cattle and buffaloes (Lubinsky, 1957; Tomczuk et al., 2005; Gőz et al., 2006; AlSaffar et al., 2010), and the view of (PonceGordo et al., 2008) who stated that"it is a common mistake on identifying any ciliates in feces of animals as B. coli".

Concerning the pathogencity of B. sulcata, it is controversial either it is a commensal or pathogeneic as it was noticed that high intensity of B. sulcata was associated with diarrhoea in ruminants (Yaşar Gőz et al., 2006; Al-Saffar et al., 2010), but it is not clear if it is a real cause of dirrhoea or not.

Urman and Kelly (1964) reported a case of dead cow with ulcerative colitis, histological examination showed presence of blood cells and debris within the food vacuole of $B$. sulcata invaded the epithelium and sub-epithelial layers of colon, but they did not accuse B. sulcata as a cause of death or colitis. Later, Tomczuk et al., (2005) claimed that $B$. sulcata has similar behavior to $B$.coli as a cause of diarrhoea in cattle. Balantidium spp. could produce balantidial dysentery in man and diarrhoea in animals (Wenyon, 1926; Levine, 1985; PonceGordo et al., 2008), meanwhile, the pathogenesis of balantidial dysentery is not fully understood (Schuster and Ramirez-Avila, 2008).

The differentiation between the cyst stages of $B$. sulcata and B. coli is difficult due to overlapping in size and the absence of characteristic feature especially in aged cysts, the most frequently stage found is cyst, which complicates the differentiation.

In conclusion, this preliminary repot highlights the situation of B. sulcata in Egypt. Further and excessive study to identify the exact species of intestinal ciliates in different ruminant animals and clarify its nature are required and encouraged.

\section{References}

Abubaker, M. I.; Nayel, M. N.; Fadlalla, M. E., Abdelrahman, A. O.; Abuobeidea S. A. and Elgabara, Y. M. (2000): Prevalence of gastrointestinal parasites in young camels in Bahrain. evue Élev Méd vét Pays trop, 53 (3): 267-271.

Al-Saffar, T. M.; Suliman, E. G. and Al-Bakri, H. S. (2010): Prevalence of intestinal ciliate Buxtonella sulcata in cattle in Mosul. Iraqi J of Vet Med, Vol. 24, No. 1: 27-30.

Becker, E. R. (1932): The present status of problems relating to the ciliates of ruminants and Equidae. The Quarterly Rev of Biol; 7 (3): 282-297.

Bilal, C. Q.; Kahn, M. S.; Aviaz, M.; Ijaz, M. and Khan, J. A. (2009): Prevalence and chemotherapy of Balantidium coli in cattle in the River Ravi reigon, Lahore (Pakistan). Vet Parasitol, 163: 15-17.

Cooper, H. and Gulati, A. (1926): On the occurrence of Isospora and Balantidium in cattle. Me. Dept Agric India, Calcutta, Vet Ser 3: 191-193.

Garcia, L. S. (1999): Practical Guide to Diagnostic Parasitology. American Soci of Microbiol publications, Washington, DC.

Goz, Y.; Altug, N.; Yuksek, N. and Zkan, C. (2006): Parasites detected in neonatal and young calves with diarrhoea. Bull. Vet Inst Pulway, 50: 345-348.

Headley, S.A,; Kummala, E. and Sukura, A. (2008): Balantidium coli-infection in a Fannish horse. Vet Parasitol; 158: 129-132.

Hong, Ki-Ok and Youn, Hee-Jeong (1995): Incidence of Buxtonella sulcata from cattle in Kyonggi-do. Kor J Parasitol., 33(2): 135-138.

Jameson, A. P. (1926): A ciliates, Buxtonella sulcata n.g., n.sp., from the caecum of cattle. Parasitol.18: 182-186.

Jiménez, A. E.; Fernández, A., Alfaro, R., Dolz, G., Vargas, B., Epe, C. and Schnieder, T. (2010). A crosssectional survey of gastrointestinal parasites with dispersal stages in feces from Costa Rican dairy calves. Vet Parasitol, 
173 (3-4): 236-246.

Kudo, R. R. (1931): Handbook of Protozology. Charles Thomas publisher, pp369.

Lapage, G. (1956): Veterinary Parasitology. Oliver and Boyd Ltd., London, pp. 908.

Levine, N. D. (1985): Veterinary Protozoology. Iowa State University Press, Ames, pp. 334-364.

Lubinsky, G. (1957): Buxtonella sulcata (Ciliata: Holotricha), a parasite of Bos indicus and Bubalus bubalus in the western Punjab. Can J Zool, 35: 545-548.

Lynn, D. H. (2008): The Ciliated Protozoa. Characterization, Classification and Guide to Literature. The $3^{\text {rd }}$ Ed, Springer Science; pp. 347.

Mamatha, G. S. and Placid, E. D. (2006): Gastrointestinal Parasitism of cattle and buffaloes in and around Bangalore. J of Vet Parasitol, 20 (2).

Ndao, M. (2009): Diagnosis of parasitic diseases: old and new approaches. Interdisciplinary Persp on Infectious Dis; pp. 1-15.

Ponce-Gordo, F.; Jimenez-Ruiz, E. and Martínez-Díaz, R.A. (2008): Tentative identification of the species of
Balantidium from ostriches (Struthio camelus) as Balantidium coli-like by analysis of polymorphic DNA. Vet Parasitol, 157: 41-49.

Rees, C. W. (1930): Studies on the morphology and behavior of Buxtonella sulcata from cattle and of Balantidium coli from the pig. Parasitol, 22: 314-325.

Schuster, F. L. and Ramirez-Avila, L. (2008): Current world status of Balantidium coli.Clin Microbiol Rev, 21(4): 626-638.

Tomczuk, K.; Kurek, L.; Stec, A.; Studzinska, M. and Mochol, J. (2005): Incidence and clinical aspects of colon ciliates Buxtonella sulcata infection in cattle. Bull Vet Inst. Pulway, 49: 23-33.

Wenyon, C. M. (1926): Protozoology. A Manual for Medical Men, Veterinarian and Zoologists. Baillie`re, Tindall and Cox, London, pp 1563.

Urman, H. D. and Kelly, G. W. (1964): Buxtonella sulcata a ciliate associated with ulcerative colitis in a cow and prevalence of infection in Nebraska cattle. Iowa State Univ Vet, 2: 118-122. 